\title{
Review of 12 Principles of Green Chemistry in Practice
}

\author{
Anita Ivanković ${ }^{1}$, Ana Dronjić́ ${ }^{1}$, Anita Martinović Bevanda ${ }^{2}$, Stanislava Talić $^{2}$ \\ ${ }^{1}$ Faculty of Agronomy and Food Technology, University of Mostar, Mostar, Bosnia and Herzegovina \\ ${ }^{2}$ Department of Chemistry, Faculty of Science and Education, University of Mostar, Bosnia and Herzegovina, Mostar, Bosnia and \\ Herzegovina
}

\section{Email address:}

anitaivankovic@gmail.com (A. Ivanković), adronjic@gmail.com (A. Dronjić), anita.martinovic161@gmail.com (A. M. Bevanda), stanislavatalic@gmail.com (S. Talić)

\section{To cite this article:}

Anita Ivanković, Ana Dronjić, Anita Martinović Bevanda, Stanislava Talić. Review of 12 Principles of Green Chemistry in Practice. International Journal of Sustainable and Green Energy. Vol. 6, No. 3, 2017, pp. 49-48. doi: 10.11648/j.ijrse.20170603.12

Received: June 16, 2017; Accepted: July 4, 2017; Published: July 26, 2017

\begin{abstract}
This paper provides an overview of aplicability 12 principles and future trends of Green Chemistry. Green or Sustainable Chemistry is a term that refers to the creation of chemical products and processes that reduce or eliminate the use and production of harmful substances. They are used exclusively chemicals and chemical processes that do not have negative consequences for the environment. It is based on twelve principles that can be used to initially create or recreate molecules, materials, reactions and processes that are safer for human health and the environment. The processes of the Green Chemistry that have been developed to date include almost all areas of chemistry, including organic, inorganic, biochemistry, polymer, toxicology, environmental, physical, technological, etc. Through the several prevailing trends of the green program such as catalysis, biocatalysis and the use of alternative: renewable feedstock (biomass), reaction media (water, ionic liquids and supercritical fluids), reaction conditions (microwave irradiation) and new synthetic pathways (photocatalytic reaction), the dual goals - environmental protection and economic benefit can be achieved. This article shows examples of the prevailing trends in ways that Green Chemistry reduces the impact of chemical processes and technologies on the environment.
\end{abstract}

Keywords: Green Chemistry, Biocatalysis, Biomass, Ionic Liquids, Supercritical Fluids, Microwave Irradiation, Photocatalysis

\section{Introduction}

Accelerated progress in science and technology in the second half of the twentieth century has led to significant economic development and an increase in living standards in developed parts of the world. However, such economic development has also caused considerable environmental degradation, which is manifested by more pronounced climate change, the emergence of ozone holes and the accumulation of non-destructive organic pollutants in all parts of the biosphere. The newly established situation required the search for a solution to balance the use of natural resources, economic growth and environmental conservation.

As a result of such reflections in the last two decades, awareness of the need for environmental protection has increased, so great attention is paid to the so-called "Green and viable technologies. The new laws and regulations aim to protect the ecosystem from harmful chemicals, while the chemical community through the processes of green chemistry is geared towards developing new compounds and processes that are less dangerous to human health and the environment.

Green or Sustainable Chemistry is a term related to the creation of chemical products and processes that reduce or eliminate the use and production of harmful substances. As a new branch of chemistry with ecological approaches it involves reducing or eliminating the use of harmful substances in chemical processes as well as reducing harmful and toxic intermediates and products.

To be called "green," each reaction should have three green components: solvent, reagent / catalyst and energy consumption.

Green chemistry is based on twelve principles that can be used to create or recreate molecules, materials, reactions and processes that are safer for human health and the 
environment, and the processes of green chemistry developed to date include mainly all areas of chemistry, including Organic, inorganic, biochemical, polymeric, toxicological, environmental, physical, technological, etc.

Basic principles of green chemistry cover a wide spectrum of synthetic organic synthesis: designing processes in organic synthesis to reduce byproduct/waste generation, reduce the use of hazardous chemicals/raw materials and enhance the use of safer or more environmentally-safe solvents and (bio) catalysts, renewable raw materials and how Would improve energy efficiency. In addition, green chemistry is interested in the best form of waste disposal and designing the process of degradation of chemical products after use, all in accordance with pollution prevention and sustainable development measures [1].

The goals of green chemistry in environmental protection and economic profit are achieved through several dominant directions such as catalysis, biocatalysis, the use of alternative renewable raw materials (biomass), alternative reaction media (water, ionic liquids, supercritical fluids), alternative reaction conditions (microwave activation, Mechanochemistry and ultrasound) as well as new photocatalytic reactions $[2,3]$.

This paper aims to contribute to a better understanding of the principles and processes underlying green chemistry, and through examples and dominant trends to point to the ways in which green chemistry reduces the impact of chemical processes and technology on the environment.

\section{Green Chemistry}

(Green color is the color of chlorophyll and the color of the dollar. Being a green series of years is a battleground of environmental activists, and becoming a green becoming a trend in product marketing. And for chemists it becomes imperative to be green in applying the principles of green chemistry in all aspects of chemical sciences, in fundamental and applied research, production and education. [4].

\subsection{Definition of Green Chemistry}

According to the EPA definition, green chemistry is defined as a chemistry that designs chemical products and processes that are harmless to the environment, thus preventing the formation of pollution. Chemical products should be made so that they do not remain in the environment at the end of their application and that they are broken down into components that are harmless to the environment. Saving based on efficient synthesis without the use of "exotic" reagents, reducing the required energy, and replacing organic solvents with water are significant even at the laboratory level, while in industrial scale possible millions of savings [5].

Green chemistry is not a separate scientific discipline, but a responsible interdisciplinary approach to science, based on chemical, ecological and social responsibility, which enables creativity and the advancement of innovative research [6]. As a propulsive area of research, it tries to find and maintain a balance between the use of natural resources, economic growth and environmental conservation.

\subsection{Trends in Green Chemistry}

Green chemistry "program for the design, development and application of chemical products and processes that reduce or eliminate the use or production of substances that are hazardous to human health and the environment" and to achieving the main goals of the green program comes through several dominant trends [2]:

a. Research in the field of catalytic and biocatalytic reactions in order to obtain highly selective, pure compounds without the formation of toxic byproducts;

b. Seeking new raw materials, harmless and renewable, such as biomass;

c. Designing less toxic eco-compatible chemicals;

d. Finding and testing new alternative, non-toxic and renewable reaction media such as water, ionic liquids and supercritical fluids

e. Finding and testing new alternative reaction conditions, such as microwave, ultrasound and light reacting

f. Exploration of alternative routes for the purification of poisoned air and water to improve their quality, such as photocatalytic reactions [2].

Realizing the set goals, "green chemistry changes steady industrial practice - produces, pollutes, and then cleanses, and in the late twentieth century becomes the heart and soul of industrial ecology" [2].

Green chemistry is a Hippocratic oath for chemists, and in order to preserve natural resources and the environment, a new generation of scientists and technologists is being developed, which economically analyze the processes and materials used in production and development.

Green chemistry or ecologically harmless, harmless and sustainable chemistry is the manufacture and application of chemical products and processes that reduce or eliminate the use and creation of hazardous substances. Instead of limiting the risk by controlling exposure to harmful chemicals, green chemistry seeks to reduce, and possibly eliminate, the danger, denying the need for exposure control. If no hazardous substances are used or produced, then the risk is zero and there is no need to worry about removing hazardous substances from the environment or limiting exposure to them or "Green chemistry is about reducing waste, raw materials, risks, energy, environmental impact and cost" [2].

\section{12 Principles of Green Chemistry}

Twelve principles of green chemistry have been developed by Paul Anastas and John Warner of EPA, and in their Green Chemistry Theory and Practice book, 1998, they explained their meaning in practice.

The principles of green chemistry speak about the reduction or removal of dangerous or harmful substances from the synthesis, production and application of chemical products and thus the use of substances dangerous to 
human health and the environment is reduced or eliminated. When designing a green chemistry process, it is impossible to meet the requirements of all twelve principles of the process at the same time, but it attempts to apply as many principles as possible during certain stages of synthesis.

\subsection{Prevention}

It is better to prevent waste than to treat or clean up waste after it has been created.

The first principle of green chemistry is the principle of prevention, ie the prevention of waste generation, which is more favorable for humans and the environment, and ultimately cheaper than treating waste and destroying it after it has emerged.

The justification for the introduction of this principle is confirmed by the fact that around 12 billion tonnes of waste, or about 300 million tonnes of hazardous waste for human health and the environment (so-called hazardous waste) are produced annually in the United States. The chemical industry produces 70 percent of the total amount of hazardous waste and the highest organic toxic waste (about 150,000 tons) with methanol and xylenes prevailing. Waste sanitation "consumes about 2.2 percent of gross US product, and costs continue to grow". Organic waste, which is harmful to humans and the environment, is primarily produced at certain stages of synthesis, so-called. "Dirty reactions" during which toxic reactants and solvents are used, and due to the harsh reaction conditions, a large number of toxic byproducts are formed. These are the most common basic reactions of organic synthesis (halogenation, oxidation, alkylation, nitration and sulfonation) that are applied in different industrial branches [7].

Although the chemical industry, as well as other chemical manufacturers, have long ago avoided prevention, the interest of green chemistry and the community is precisely to prevent waste generation. However, the absolute prevention of waste generation in practice is virtually impossible since no input raw material can be fully utilized. On the other hand, one waste disposed of represents the final loss of material goods in the circular flow: production - consumption. Therefore, any return of material goods to a circular stream represents a pure economic gain and it is necessary to think first whether it is possible to prevent the generation of waste and if it is not necessary to devise the way in which the amount of waste produced in production can be utilized in the best possible way, so it becomes useful.

This approach to the problem has brought positive results: the paint and varnish industry already produces solvent-free paints and lacquers. The detractors industry has already thrown out all phosphorus-containing detergents. Asbestos is no longer used in practice.

Along with finding new medicines, one of the biggest challenges of the pharmaceutical industry is to design and apply procedures that have minimal environmental impact in the manufacturing process. This primarily means reducing the amount of waste generated in production processes. Since nearly $80 \%$ of waste in the pharmaceutical industry is associated with solvents, and that about $60 \%$ of their energy is consumed, the solution is to reduce the use of solvents. A good example is the new "green" production process of sertraline (Figure1) by which the introduction of ethanol as the sole solvent eliminates the need for the use, distillation and recovery of four solvents (methylene chloride, tetrahydrofuran, toluene and hexanes) resulting in a reduction in solvent consumption of 250 to 25 liters per $\mathrm{kg}$ of sertraline [8].
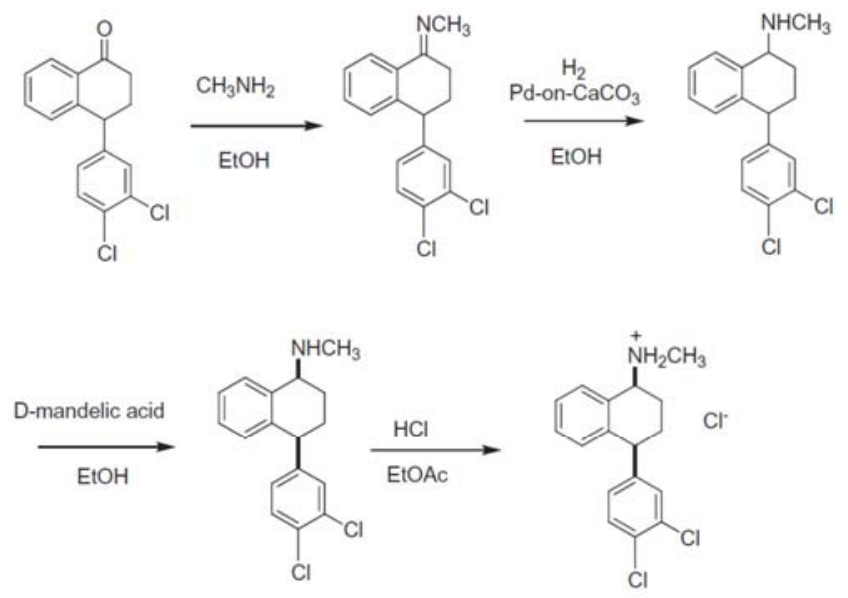

Sertraline $\mathrm{HCl}$ salt

Figure 1. "Green"'hesis of sertraline [8].

\subsection{Atom Economy}

Synthetic methods should be designed to maximize the incorporation of all materials used in the process into the final product.

The principle of Atom Economy is logically linked to the principle of waste prevention, since it requires all raw materials used in production to maximize utilization or inclusion in the final product to ultimately reduce the amount of waste. This means that the chemical synthesis should be designed in such a way that the final product maximizes the input of raw materials or design such synthetic products that will use the entire material used for synthesis in the final product.

The principle of increasing atomic usability was defined in 1991 by Barry Trost of Stanford University. Trost believes that introducing the concept of usability atoms is essentially the prevention of waste at the molecular level. Barry Trost's concept initiated the redesign of existing synthetic reactions until then established on the principle of "making a product regardless of price". These modifications are useful and because they generally lead to increased yields.

There is a known progress in the synthesis of ibuprofen [9]. The main problem of old synthesis (boots process) is low economic cost, because the utilization of input raw materials is only about $40 \%$. In the 1990 s a new "green" method of ibuprofen synthesis was developed, involving only three steps, and almost all transitional materials were converted to 
the product (up to $99 \%$ ) or regenerated and returned in the process and almost almost eliminated the generation of waste materials And this process is one of the processes of "green synthesis" $[10,11]$.

Figure 2 shows a comparative comparison of classic Boots and the "green" Hoechst synthesis of ibuprofen.

The new process has much higher atomic efficiency and almost no waste (waste materials are recycled in the process) thus contributing to pollution prevention.

Atom economy is defined as the ratio of relative molecular masses of the desired product and all reactants expressed in percentages.

$\%$ of atomic efficiency $=(\mathrm{Mr}$ of the desired product $/ \mathrm{Mr}$ of all reactants) $\times 100$

The Boots synthesis consists of six synthetic steps and yields $40 \%$, while the Hoechst process of obtaining ibuprofen consists of only three steps and yields a reaction of $77 \%$, namely $99 \%$ if the fact that the acetic acid is formed in the first The synthesis step is extracted and reused in production. That is why Hoechst is a more economical and greener way to get ibuprofen. In Tables 1 and 2, a comparison of the Boots process and the "green" Hoechst process of ibuprofen synthesis according to atomic viability.

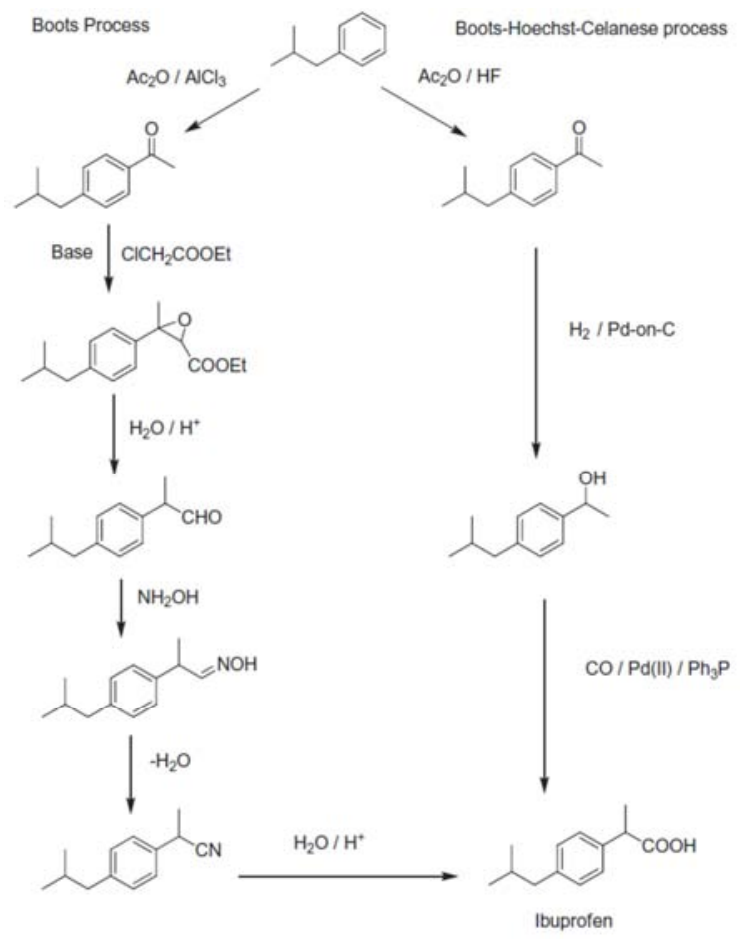

Figure 2. Comparison of the Boots Process and the "Green" Hoechst Ibuprofen Synthesis Process [8].

Table 1. Effectiveness of Atoms in the Green "Hoechst" Process of Ibuprofen Synthesis [8].

\begin{tabular}{llllll}
\hline Reactant & & \multicolumn{2}{c}{ Used in Ibuprofen } & Not used in ibuprofen \\
\hline Formula & Relative molecular mass $\left(\mathbf{M}_{\mathbf{r}}\right)$ & Formula & Relative molecular mass $\left(\mathbf{M}_{\mathbf{r}}\right)$ & Formula & Relative molecular mass (M \\
\hline $\mathrm{C}_{10} \mathrm{H}_{14}$ & 134 & $\mathrm{C}_{10} \mathrm{H}_{13}$ & 133 & $\mathrm{H}$ & 1 \\
$\mathrm{C}_{4} \mathrm{H}_{6} \mathrm{O}_{3}$ & 102 & $\mathrm{C}_{2} \mathrm{H}_{3}$ & 27 & $\mathrm{C}_{2} \mathrm{H}_{3} \mathrm{O}_{3}$ & 75 \\
$\mathrm{C}_{4} \mathrm{H}_{7} \mathrm{ClO}_{2}$ & 122,5 & $\mathrm{CH}$ & 13 & $\mathrm{C}_{3} \mathrm{H}_{6} \mathrm{ClO}_{2}$ & 109,5 \\
$\mathrm{C}_{2} \mathrm{H}_{5} \mathrm{ONa}$ & 68 & & 0 & $\mathrm{C}_{2} \mathrm{H}_{5} \mathrm{ONa}_{2}$ & 68 \\
$\mathrm{H}_{3} \mathrm{O}$ & 19 & & 0 & $\mathrm{H}_{3} \mathrm{O}$ & 19 \\
$\mathrm{NH}_{3} \mathrm{O}$ & 33 & & 0 & $\mathrm{NH}_{3} \mathrm{O}$ & 33 \\
$\mathrm{H}_{4} \mathrm{O}_{2}$ & 36 & $\mathrm{HO}_{2}$ & 33 & $\mathrm{H}_{3}$ & 3 \\
$\mathrm{Total}$ & & $\mathrm{Ibuprofen}_{20}$ & $\mathrm{Production} \mathrm{waste}^{3}$ & \\
$\mathrm{C}_{20} \mathrm{H}_{42} \mathrm{NO}_{10} \mathrm{ClNa}$ & 514,5 & $\mathrm{C}_{13} \mathrm{H}_{18} \mathrm{O}_{2}$ & 206 & $\mathrm{C}_{7} \mathrm{H}_{24} \mathrm{NO}_{8} \mathrm{ClNa}$ & 308,5 \\
\hline
\end{tabular}

$\%$ atom economy $=(206 / 514,5) \times 100=40 \%$

Table 2. Effectiveness of Atoms in the Green "Hoechst" Process of Ibuprofen Synthesis [8].

\begin{tabular}{llllll}
\hline Reactant & & Used in Ibuprofen & \multicolumn{2}{l}{ Not used in ibuprofen } \\
\hline Formula & Relative molecular mass $\left(\mathbf{M}_{\mathbf{r}}\right)$ & Formula & Relative molecular mass $\left(\mathbf{M}_{\mathbf{r}}\right)$ & Formula & Relative molecular mass (M \\
\hline $\mathrm{C}_{10} \mathrm{H}_{14}$ & 134 & $\mathrm{C}_{10} \mathrm{H}_{13}$ & 133 & $\mathrm{H}$ & 1 \\
$\mathrm{C}_{4} \mathrm{H}_{6} \mathrm{O}_{3}$ & 102 & $\mathrm{C}_{2} \mathrm{H}_{3}$ & 43 & $\mathrm{C}_{2} \mathrm{H}_{3} \mathrm{O}_{2}$ & 59 \\
$\mathrm{H}_{2}$ & 2 & $\mathrm{H}_{2}$ & 2 & 0 & 0 \\
$\mathrm{CO}$ & 28 & $\mathrm{CO}$ & 0 & Production waste \\
Total & & Ibuprofen & & $\mathrm{C}_{2} \mathrm{H}_{4} \mathrm{O}_{2}$ & 60 \\
$\mathrm{C}_{15} \mathrm{H}_{22} \mathrm{NO}_{4}$ & 266 & $\mathrm{C}_{13} \mathrm{H}_{18} \mathrm{O}_{2}$ & 206 & & \\
\hline
\end{tabular}

$\%$ atom economy $=(206 / 266) \times 100=77 \%$

The E-factor is used to compare the process of comparing the proportions of waste materials and the desired product. The calculation of the E-factor is determined by the ratio of mass of waste $(\mathrm{kg})$ per unit of product in kilograms [12]

E-factor $=\mathrm{kg}$ of waste $/ \mathrm{kg}$ of product

And represents "the actual amount of waste generated in the process, including the losses of solvents, acids and bases used in the work and, in principle, waste from energy production". Waste includes products that do not have any further use, but also reagents and solvents used during production and are not recycled or recycled.

Sheldon points out that the use of E-factors varies greatly between the chemical industry and states that the "good" E factor usually spends around 0.1 , meaning that $10 \mathrm{~kg}$ of the desired product is only $1 \mathrm{~kg}$ of waste and by-products [12]. In pharmaceutical production, when essential for high purity products, the E-factor can be 100 , which means that every $\mathrm{kg}$ of product produces $100 \mathrm{~kg}$ of waste. However, the actual 
amount of waste also depends on the quantities of the product. Even with a much lower E-factor, the oil industry produces higher amounts of waste than pharmaceutical production where the E-factor is high but is significantly lower in production. Table 3 shows E-factors of various sectors of the chemical industry.

Table 3. E-factor in chemical industry [8].

\begin{tabular}{llll}
\hline Industry & Product (t) & E-factor & Waste (t) \\
\hline Rafinery & $10^{6}-10^{8}$ & cca 0,1 & $10^{5}-10^{7}$ \\
Salts & $10^{4}-10^{6}$ & $<1-5$ & $10^{4}-5 \times 10^{6}$ \\
Fine chemicals & $10^{2}-10^{4}$ & $5-50$ & $5 \times 10^{2}-5 \times 10^{5}$ \\
Pharmaceuticals & $10-10^{3}$ & $25-100$ & $2.5 \times 10^{2}-10^{5}$ \\
\hline
\end{tabular}

\subsection{Less Hazardous Chemical Syntheses}

Wherever practicable, synthetic methods should be designed to use and generate substances that possess little or no toxicity to human health and the environment.
Most chemical synthesis reactions, which usually take place in multiple stages, use toxic reagents. Although the product does not contain these toxic substances, there is a risk of its contamination and redesigning these processes is a task of green chemistry.

The Less Hazardous Chemical Synthesis advocates, wherever possible, the creation of synthetic methods for the use and creation of substances that are little or no toxic to human health and the environment. Replacing harmful chemicals with biological enzymes makes many industrial processes cleaner and cheaper [6].

As an example, a new Asahi Kasei's polycarbamate synthesis (PC) process is conceptually simple, based on the substitution of toxic carbonyl dichloride $\left(\mathrm{COC}_{2}\right)$ with $\mathrm{CO}_{2}$. This process also results in the removal of dichloromethane $\left(\mathrm{CH}_{2} \mathrm{Cl}_{2}\right)$ as a solvent. The total reaction consists of ethylene oxide $\left(\mathrm{CH}_{2}\right)$ 20, $\mathrm{CO}_{2}$ and bisphenol- $\mathrm{A}\left(\mathrm{C}_{15} \mathrm{H}_{16} \mathrm{O}_{2}\right)$ to give polycarbamate and ethylene glycol $\mathrm{C}_{2} \mathrm{H}_{6} \mathrm{O}_{2}$ [13].

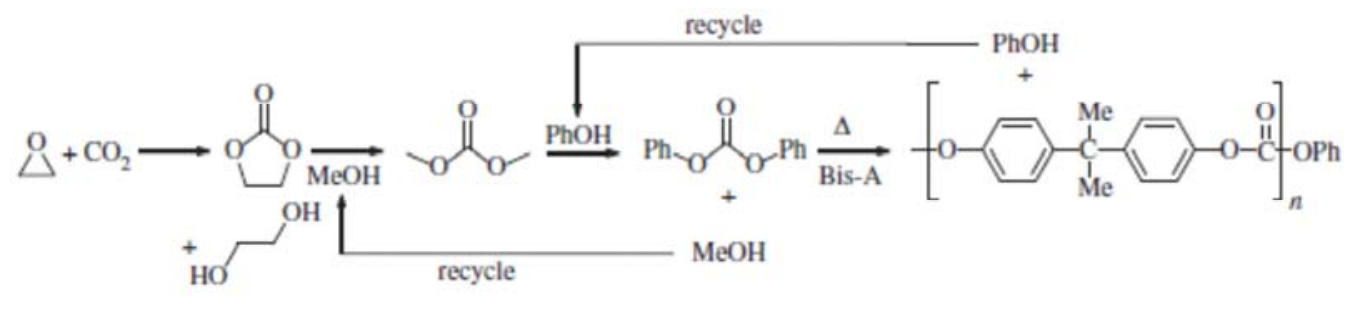

Figure 3. Synthesis of polycarbamate [11].

\subsection{Designing Safer Chemicals}

Chemical products should be designed to effect their desired function while minimizing their toxicity.

Minimizing toxicity, while maintaining function and efficiency, can be one of the most challenging aspects of designing safer products and processes, and achieving that goal requires understanding not only chemistry but also the principles of toxicology and environmental science.

Designing Safer Chemicals advocates the design of chemical products in a way that reduces their toxicity and maintains their effectiveness. The goal of producing safe chemicals (non-carcinogenic, mutagenic, neurotoxic) is the balance between optimal performance and chemical product function, ensuring that toxicity and risk are reduced to the lowest possible level. In other words, the use of toxic chemicals should be avoided and replaced inhospitable wherever possible, but should take account of their efficacy.

This principle is used in the development of new insecticides and pesticides that are specific to target organisms, ie they are toxic only to target organisms and decompose into environmentally harmless substances. Another example is the use of highly toxic organic tin-based organic compounds ( $\mathrm{Sn})$, previously coated on the outside to prevent the capture of seaweed and plankton. These organic compounds have been replaced by a product called Sea-Nine which is completely degradable and non-toxic. Also, an example is the development of oxidant activator for hydrogen peroxide. This allows replacement of chlorine bleaches (preparations that damage the ozone layer) by hydrogen peroxide in paper production [6].

An example is the production of polymers of polyphenylene sulfone (PPSU), which is now widely used for indoor airplanes and is also introduced in underground trains where it is also important to use non-flammable materials. It is a new engineering plastic characterized by a unique combination of useful environmental, mechanical, and flame resistant properties [14].

\subsection{Safer Solvents and Auxiliaries}

The use of auxiliary substances (e.g., solvents, separation agents, etc.) should be made unnecessary wherever possible and innocuous when used.

Chromatographic separations, where large quantities of solvents are used, are problematic due to environmental pollution. Most conventional organic solvents are toxic, flammable and corrosive. Their recycling is linked to energyefficient distillation with considerable losses and therefore the development of environmentally-friendly solvents is necessary.

Safer Solvents and Auxiliaries recommends that the process of synthesis be maximally reduced and, whenever possible, avoid the use of auxiliary chemical substances (eg solvents, separating agents, etc.) When used they should be harmless. According to the principles of green chemistry, the choice of suitable substitutions for organic solvents is based on: worker safety, process safety, environmental safety and sustainability of the process. The solvent should be chemically and physically stable, low volatility, easy to use 
and easy to recycle.

According to the suitability of use, conventional solvents are suitable, usable, and undesirable (Table 4).

Table 4. Solvent selection according to usability [15].

\begin{tabular}{lll}
\hline Suitable & Usable & Undesirable \\
\hline methanol & cyclohexane & pentane \\
ethanol & methylcyclohexane & hexane \\
propan-1-ol & heptane & diisopropyl ether \\
propan-2-ol & isooctane & dichloromethane \\
butan-1-ol & t-Butyl methyl ether & chloroform \\
t-butanol & acetonitrile & benzene \\
ethyl acetate & tetrahydrofuran & dimethyl acetate \\
isopropyl acetate & acetic acid & carbon tetrachloride \\
acetone & xylene & dimethoxyethane \\
methyl ethyl ketone & toluene & pyridine \\
\hline
\end{tabular}

For now, it is promising to replace the known organic solvents with recyclable solvents, which are ionic liquids salts at room temperature in the liquid state. Unlike volatile organic compounds, ionic liquids have low vapor pressure, do not vaporise and do so easily, resulting in safer chemical processes [16].

\subsection{Design for Energy Efficiency}

Energy requirements of chemical processes should be recognized for their environmental and economic impacts and should be minimized. If possible, synthetic methods should be conducted at ambient temperature and pressure.

The oil crisis in 1973 has initiated the development of a number of processes in which energy savings are taken into account, with the aim of exploiting every $\mathrm{kJ}$ of energy in the production process. Following the above-mentioned Principle of Energy Efficiency, whose other name is Design for Energy Efficiency, as a fundamental requirement, minimizes the use of energy. Table 5 shows possible ways to improve energy efficiency in the chemical industry [17].

Table 5. Improving Energy Efficiency in the Chemical Industry.

\begin{tabular}{ll}
\hline $\begin{array}{l}\text { Maintenance and } \\
\text { recovery }\end{array}$ & $\begin{array}{l}\text { Good insulation and well-maintained equipment reduce heat and energy losses. Waste generated by chemical processes often has } \\
\text { an energy value and can be converted into useful fuel for office heating and hot water production. In some cases this heat can be } \\
\text { shared with the local community. }\end{array}$ \\
$\begin{array}{l}\text { It is necessary to choose the reactions and catalysts that require lower temperatures. In order to minimize energy requirements, } \\
\text { the principle of increasing energy efficiency advocates the process of synthesis at room temperature and atmospheric pressure, } \\
\text { choice and conditions } \\
\text { whereby the use of catalyst is of great use. Catalysts are developed so that the process can be run at lower temperatures and } \\
\text { pressures (high temperatures and pressures require enough energy). }\end{array}$ \\
$\begin{array}{l}\text { Production plants often generate their own cogeneration (Combined Heat and Power or CHP), which involves simultaneous } \\
\text { production of electrical and useful heat energy in a single process. It is more efficient because it eliminates the loss in } \\
\text { Power }(\mathrm{CHP})\end{array}$ & \begin{tabular}{l} 
transmission, And the excess heat released during the cogeneration process can be used on site for various purposes. \\
\hline
\end{tabular}
\end{tabular}

Tomatoes that grow in a greenhouse that is heated by the use of waste steam from a nearby chemical plant for the production of ammonia. Since $\mathrm{CO}_{2}$ concentrations in greenhouses fall below $50 \%$, plant growth can be achieved, and by extrusion from greenhouse gas, carbon dioxide is used as a tomato seed growth bi-activator [18].

\subsection{Use of Renewable Feedstocks}

A raw material or feedstock should be renewable rather than depleting whenever technically and economically practicable.

The seventh principle of green chemistry advocates Use of Renewable Feedstocks wherever it is technically and economically acceptable. For example, it is more convenient to use renewable raw materials than a variety of plastic materials, and then to waste away the waste materials. Because of this, the making of biodegradable plastic materials is a current trend. Biodegradable packaging has a future in the food industry. Numerous factors, including politics and changes in legislation, as well as global demand for food and energy resources, certainly affect the development of biodegradable packaging [19]. The principle also implies the use of renewable energy technologies that include solar energy, wind power, hydropower, biomass energy and biofuels. Over the past ten years, significant progress has been made in the development of fuels, chemicals and materials from renewable raw materials. For example, Brazil with its sugar cane production and bioethanol production ensures energy independence and employment while Europe's biodiesel is produced from rapeseed oil.

In the case of bioplastics, the use of renewable raw materials in production positively affects energy consumption and $\mathrm{CO}_{2}$ emissions. Coca-Cola, a world-widescale company for the time being, manufactures bottles made of $30 \%$ polyethylene (PE) blends, while American company NatureWorks uses bottles made from lactic acid polymers (PLA) made from lactic acid, obtained by fermentation of dextrose obtained from starch, Most commonly corn. About $1 \mathrm{~kg}$ of PLA requires about $2.5 \mathrm{~kg}$ of corn [20].

\subsection{Reduce Derivatives}

Unnecessary derivatization (use of blocking groups, protection/ deprotection, temporary modification of physical/chemical processes) should be minimized or avoided if possible, because such steps require additional reagents and can generate waste.

One of the key principles of green chemistry in the synthesis of target molecules is to avoid the use of chemical derivatives (Reduce Derivatives). The principle advocates, wherever possible, the avoidance of physical-chemical processes in which blocking and unblocking of appropriate groups during the synthesis are used, that is, whenever possible, the biological processes in the synthesis should be 
used to avoid synthesis of the products for which they are not There are enzymes to degrade them. If possible, it is necessary to reduce or avoid unnecessary derivatization (group blocking, protection / elimination protection, temporary physicochemical modification) because such steps require additional reagents and can generate waste.

Typical example is the production of antibiotics (Figure 4) based on penicillin or replacement of classical chemical enzymatic processes whereby the 6-aminopenicillic acid is obtained by reacting with the catalyzed immobilized enzyme penicillin amide. This resulted in several chemical steps being replaced by an enzymatic reaction, and no longer required a low temperature $\left(-60^{\circ} \mathrm{C}\right)$, organic solvents, and completely unsuitable conditions that increased and complicated production in the case of chemical synthesis [21].

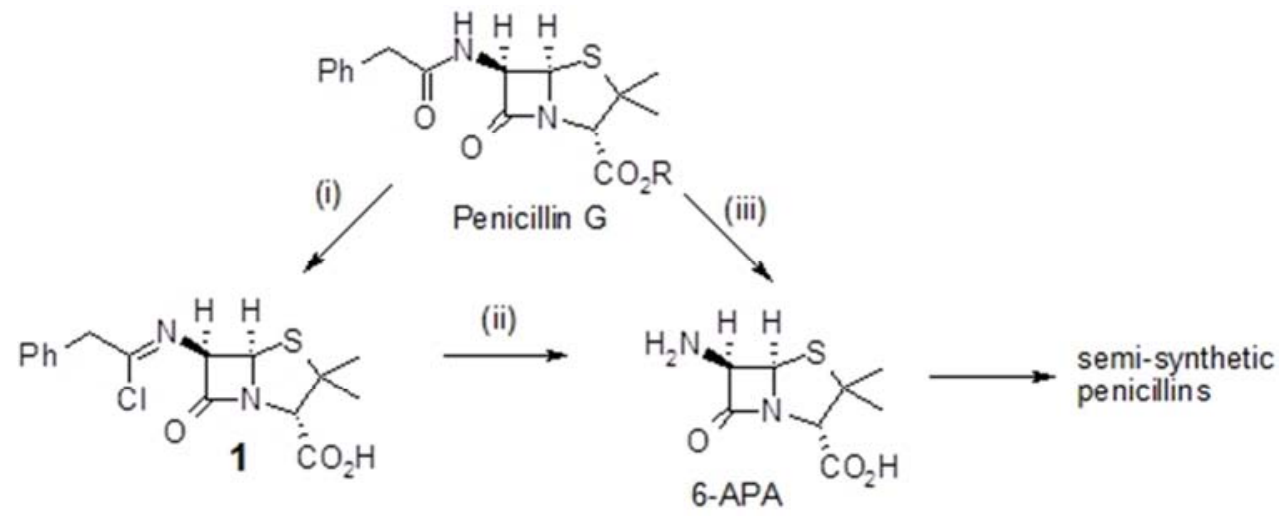

Figure 4. Synthesis of 6-aminopenicilic acid catalyzed by immobilized penicillin G amide [21].

\subsection{Catalysis}

Catalytic reagents (as selective as possible) are superior to stoichiometric reagents.

In order to protect the environment, the catalysis principle promotes the use of biodegradable catalysts, which imply less energy use, avoiding the use of organochlorine compounds and reducing the use of water or less waste water.

Like all catalysts, enzymes function in a way that lowers the activation energy of an individual reaction, and thus accelerates, up to several million times. In doing so, the enzyme remains unchanged throughout the duration of the reaction to which it affects, and this allows it to become completely unchanged when the reaction comes to an end. Also, enzymes do not affect the relative energy between the reactants and the products, nor to the related reactions.
However, what enzymes stand out among all other catalysts is their specificity in terms of stereochemistry, chemical selectivity and specificity. Compared with non-biological catalysts, biocatalysts have a great advantage given the rate of reaction, catalytic specificity, lower cost, etc., but lack of heat sensitivity and poor stability.

The classic catechol synthesis is derived from benzene (non-renewable feedstocks) in several reaction stages requiring severe reactions under which undesirable byproducts are produced. It is replaced by a biocatalytic synthesis of D-glucose (renewable raw materials) in the presence of genetically modified Escherichia coli and is performed in one reaction stage (Figure 5), no byproducts and production is economically viable [11].

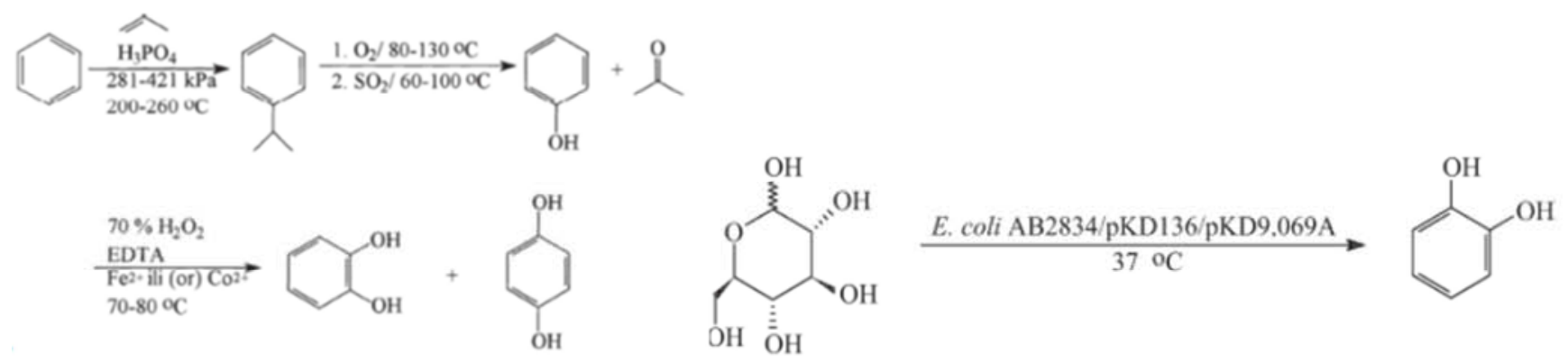

Figure 5. Catehole synthesis - classical (left) and biocatalytic (right) [22].

\subsection{Design for Degradation}

Chemical products should be designed so that at the end of their function they break down into innocuous degradation products and do not persist in the environment.

The principle of creating degradable chemicals and products or design for degradation demands the creation of chemical products that, upon termination of their activity, must be able to convert into products that are harmless to the environment.

Fulfillment of this requirement is possible by changing the technological parameters in the process management and the change of so-called. Auxiliary substances added at certain stages in the production process. The aim is to prevent the 
formation of harmful substances and to return to production as much waste as possible, which is achieved by recycling [23].

\section{Real-Time Analysis for Pollution Prevention}

Analytical methodologies need to be further developed to allow for real-time, in-process monitoring and control prior to the formation of hazardous substances.

Traditional analytical chemistry implies large amounts of sample for analysis, abundant use of solvents and energy. With the development of new methods and precision mobile instruments, it is possible that the analyzes work with a small sample size at the sampling site and with much less solvent.

The principle of Real-Time Analysis for Pollution Prevention requires further development of analytical methodology to enable real-time monitoring of the chemical production process with the aim of preventing the formation of dangerous substances, ie it is necessary to constantly monitor the production process at each stage Would prevent the occurrence of errors that could lead to the emergence of dangerous substances, harmful to the environment and human health.

Inherently Safer Chemistry for Accident Prevention

Substances and the form of a substance used in a chemical process should be chosen to minimize the potential for chemical accidents, including releases, explosions, and fires.
The Twelfth Principle of Green Chemistry is the principle of Inherently Safer Chemistry for Accident Prevention. The basic requirement is to reduce the use of substances in chemical processes that can cause adverse effects (explosion, fire and harmful vapor). An example is today the increasing use of supercritical $\mathrm{CO}_{2}$ that replaces organic solvents and which, unlike organic solvents, is not toxic or explosive and is environmentally acceptable.

Safety can be defined as a control of known hazards by achieving an acceptable level of risk and is achieved at several levels of the lowest use of Personal Protective Equipment. Then it follows the level of Administrative and Work Practice Controls) and implies establishing effective procedures, rotating work tasks, adjusting work schedules so that workers are not over-exposed to the impact of dangerous chemicals, etc. The next higher level of security control is the expert Engineering Controls, which implies the implementation of physical process change To reduce contact with hazardous chemicals, isolate the process, use wet methods to reduce dust formation, ventilation, digestion, etc. The highest level of safety control is achieved by eliminating or replacing the procedure with safer alternatives (Figure 6).

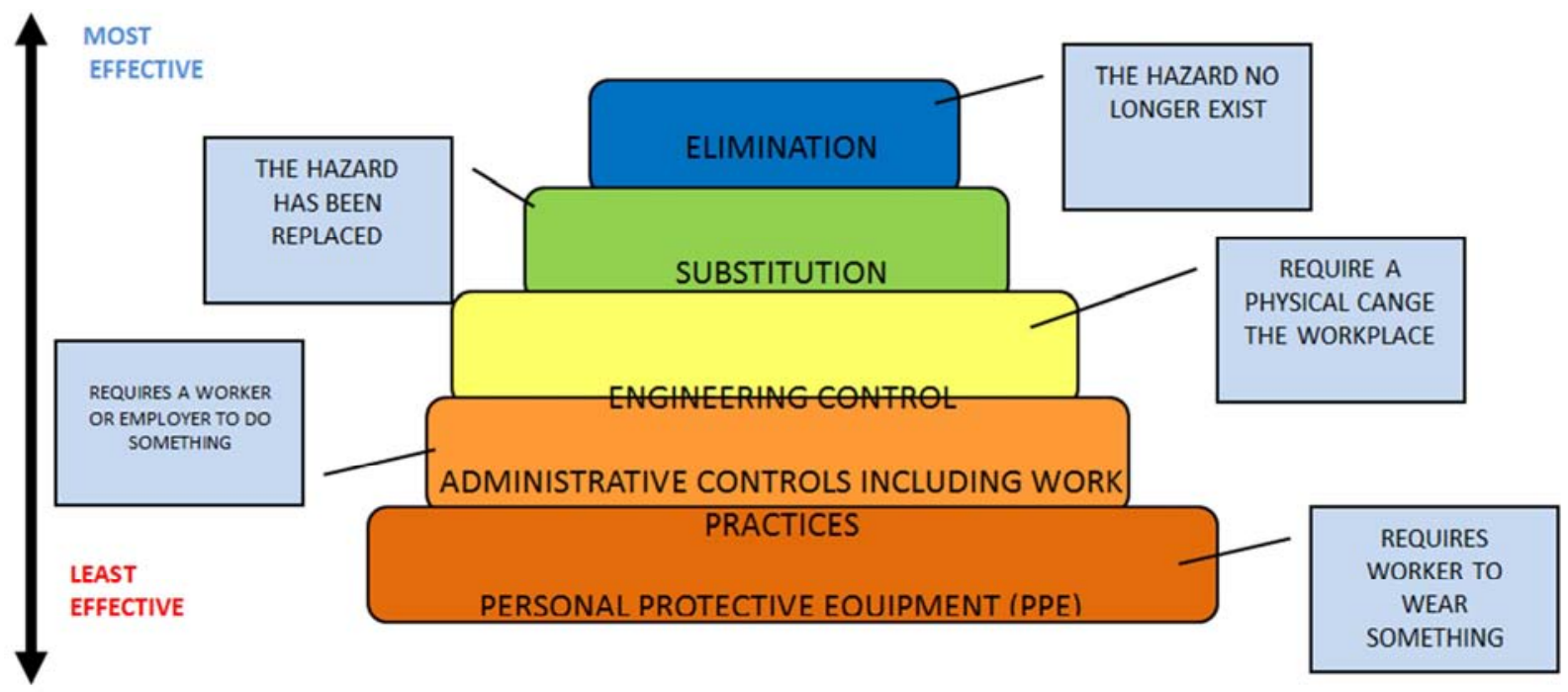

Figure 6. Hierarchy of security control.

\section{Disadvantages of Green Chemistry}

The basic task of green chemistry is designing such chemical products and processes that reduce or completely eliminate the use or creation of harmful and dangerous substances.

This goal is also the biggest handicap-lack of green chemistry that is reflected in time, costs and lack of information. More specifically, switching from an old, conventional product or process to a new "green" product or process requires a lot of time, design or redesign of a new product and process is often difficult and quite expensive, and there is also a lack of unity on what is considered safe.
With the high cost of implementation and the lack of information, the lack of green chemistry is also the fact that there is no known alternative to used chemical raw materials or alternative technologies for green processes. In addition, there is also a lack of human resources and skills.

The risks of switching to green products and processes are not divided within the supply chain, and there is a lack of resources for further research.

Ionic liquids are considered to be the future of green chemistry. Although there is no doubt that those are useful in chemical synthesis, the question is increasingly raised whether they meet expectations. When applying 12 principles that describe green chemicals, ionic liquids do not look particularly green. There is an opinion that at the present 
stage of science progress it is unrealistic to expect that in the next ten years a wide application of ionic liquids will be seen. Although, as is well known, ionic liquids are slightly volatile due to the low vapor pressure, yet it is only one of the many things that make a substance really green. For example, ionbased, imidazole-based and fluoro-anion-based liquids are likely to be poisonous but can not reach the environment by evaporation. The problem is that most ionic liquids are watersoluble and can easily reach the biosphere through that pathway [24].

\section{Conclusions}

The primary goal of each industry is to generate money from available raw materials and basic capital within sustainable industrial activities. Sustainable industrial activities must meet today's needs without jeopardizing the needs of future generations, meaning that chemical processes need to use raw materials, water and energy in a way that does not harm the environment and be economically viable.

Establishing a balance in the use of natural resources, economic growth and environmental conservation is possible through the introduction of a green chemistry process whose task is to design such chemical processes and products that are harmless to human health and the environment.

The application of the concept of green chemistry that introduces chemical safety implies adequate legal support through the legal regulation of certain procedures and activities that are unavoidable for the implementation of such a concept.

The concept of green chemistry is based on twelve principles that speak of reducing or eliminating hazardous or harmful substances from the synthesis, production and application of chemical products and thus the use of substances that are hazardous to human health and the environment is reduced or eliminated. When designing a green chemistry process, it is impossible to meet the requirements of all twelve principles of the process at the same time, but it attempts to apply as many principles as possible during certain stages of synthesis.

The goals of green chemistry in environmental protection and economic gain are achieved through several dominant directions. Some of them are: biocatalysis, catalysis, use of alternative renewable raw materials (biomass), alternative reaction media (water, ionic liquids, supercritical fluids), alternative reaction conditions (microwave activation) as well as new photocatalytic reactions.

Catalysis as the foundation of green chemistry with new catalytic reactions and types of new catalysts offers a number of benefits in terms of process utilization, selectivity, energy reduction and the use of alternative reaction media.

The huge potential of microorganisms and enzymes in the transformation of synthetic substances with selectivity gives biocatalyst a dominant position in the "green" program.

Photocatalytic reactions that represent new methods of cleaning contaminated air and water also contribute to green chemistry creating conditions for achieving sustainability.

\section{References}

[1] Valavanidis, A., Vlachogianni, T., Fiotakis, K., (2009): Laboratory Experiments of Organic Synthesis and Decomposition of Hazardous Environmental Chemicals Following Green Chemistry Principles. International Conference "Green Chemistry and Sustainable development", Thessaloniki, 25-26/9/2009. Paper for Conference Proceedings.

[2] Jukić, M., Djaković, S., Filipović-Kovačević, Ž., Kovač, V. and Vorkapić-Furač, J. (2005): Dominant trends of green chemistry. Kem Ind 54 (5): 255-272, In Croatian.

[3] Margetić, D. (2005): Mechanic-chemical organic reactions without the use of solvents. Kem Ind 54 (7-8): 351-358, In Croatian.

[4] Ritter, S. K. (2001): Green Chemistry. Chem. Eng. News, 79 (29), 27-34.

[5] Vojvodić, V. (2009): Environmental Protection: Green Manufacturing in the Pharmaceutical Industry and Cost Reduction, Kem Ind 58 (1): 32-33, In Croatian.

[6] Riđanović, L., Ćatović, F., Riđanović, S. (2013): The Green Chemistry-Ecological Revolution in the Classroom. $8^{\text {th }}$ Research/Expert Conference with International Participations "QUALITY 2013", Neum, B\&H, June 06 - 08, 447-452., In Bosnian.

[7] Jukić, M., Djaković, S., Filipović-Kovačević, Ž., and Vorkapić-Furač, J. (2004): The "green" chemistry opens up the path ecologically acceptable chemical processes. Kem Ind 53 (5) 217-224. In Croatian.

[8] Sheldon, R. A. Utilisation of biomass for sustainable fuels and chemicals: Molecules, methods and metrics. Catal Today 167, 3, 2011.

[9] Mijin, D., Stanković, M. I., Petrović, S. (2003): Ibuprofen: Gain and Properties, Hem. Ind. 57 (5) 199-214, In Serbian.

[10] Anastas, P. T., Warner, J. C. (1998): Green Chemistry Theory and Practice. New York: Oxford University Press, 10-55.

[11] Anastas, P. T., Kirchhoff, M. M., Williamson, T. C. (2001): Catalysis as a foundational pillar of green chemistry. Appl Catal A: General, 221: 3-13.

[12] Sheldon, R. A. (2007). "The E Factor: Fifteen years on". Green Chemistry. 9 (12): 1273. doi:10.1039/B713736M

[13] Welton, T. (2015): Solvents and sustainable chemistry, Proceedings of the Royal Society of London A: Mathematical, Physical and Engineering Sciences, November 11, 2015, DOI: 10.1098/rspa.0502

[14] Wayne Hill, H. and Brady, D. G. (1976): Properties, environmental stability, and molding characteristics of polyphenylene sulfide, Polymer Engineering \& Science, Vol 16, Iss 12,pp 831-835.

[15] Samori, C. (2010). Use of solvents and environmental friendly materials for applications in Green Chemistry, University of Bologna, Faculty of Mathematical, Physical and Natural Science.

[16] Kärkkäinen, J. (2007): Preparation and characterization of some ionic liquids and their use in the dimerization reaction of 2-methylpropene. Dissertation, University of Oulu. 
[17] Hoffert, M. I., Caldeira, K., Benford, G., David R. Criswell, D. R., Christopher Green, C., Herzog, H., Jain, A. K., Kheshgi, H. S., Lackner, K. S., Lewis, J. S., Lightfoot, H. D., Manheimer, W., Mankins, J. C., Mauel, M. E., Perkins, L. J., Schlesinger M. E., Volk, T., Wigley, T. (2002): Advanced Technology Paths to Global Climate Stability: Energy for a Greenhouse Planet, Science, Vol. 298, Issue 5595, pp. 981987, DOI: $10.1126 /$ science. 1072357

[18] Garnet, T. (2006): Fruit and vegetables\&uk greenhouse gas emissions:exploring the relationship, Centre for environmental strategy, University of Surrey.

[19] Ivanković, A., Zeljko, K., Talić, S., Martinović Bevanda, A. and Lasić, M. (2017): Biodegradable packaging in the food industry, Archiv für Lebensmittelhygiene 68, Heft 1.

[20] Rujnić-Sokele, M. (2007): Truths and mistakes about bioplastics. Polymers: Journal of Rubber and Plastics, Rubber and Plastics Corporation, Zagreb, 28_3: pp178-181. In Croatian.
[21] Findrik Blažević, Z. (2013): Bioreactivity Technique I, Internal Script. Zagreb: University of Zagreb, Faculty of Chemical Engineering and Technology, In Croatian.

[22] Draths, K. M., Frost, J. W. in: Anastas, P. T., Williamson, T. C. (Eds.), Green Chemistry: Frontiers in Benign Chemical Syntheses and Processes, Ch. 9, Oxford University Press, New York, 1998, pp. 150-182.

[23] Williams, R. T. (2005): Human health pharmaceuticals in the environment: an introduction, Allen Press/ACG Publishing: 145 .

[24] Bharadwaj, M. and Neelam (2015): The Advantages and Disadvantages of Green Technology, Journal of Basic and Applied Engineering Research, p-ISSN: 2350-0077; e-ISSN: 2350-0255; Volume 2, Issue 22; October-December, 2015, pp. $1957-1960$ 